\title{
Comparison of Two Methods: Problem-based Learning vs Lecture in Integrated Management of Childhood IIIness Workshops
}

\author{
${ }^{1}$ Fardin Assadi, ${ }^{2}$ Parisa Khoshnevisasl, ${ }^{3}$ Mansor Sadeghzadeh, ${ }^{4}$ Korosh Kamali
}

\begin{abstract}
Objectives: The aim of this study was to compare problembased learning (PBL) with lecture presentation in education of clinical medical students in Integrated Management of Childhood Illness (IMCl) workshops.
\end{abstract}

Materials and methods: This crossover interventional study was conducted on clinical medical students in pediatric disease department of Zanjan University of Medical Sciences. Fortyfour students were randomly divided into two groups and two subjects in IMCl courses were chosen. One of the topics was presented as lecture for the first group of students and as PBL for the second group. The second topic was presented as PBL for the first group and as lecture for the second group of students.

Results: The students' scores in intervention groups for both topics of "loss of consciousness" and "management of diarrheal diseases" were significantly higher than controls. Each student got significantly higher score in subject presented as PBL. Students preferred PBL compared to lecture for increasing their motivation, a higher quality of education, knowledge retention, and class attractiveness.

Discussion: Besides the attractiveness of PBL, it seems that this method is more successful than lecture in increasing student's knowledge. We propose to use this method in workshops and medical education in clinic and hospital wards.

Keywords: Education, Integrated management of childhood illness, Lecture, Medical student, Problem-based learning.

How to cite this article:Assadi F, KhoshnevisasI P, SadeghzadehM, Kamali K. Comparison of Two Methods: Problem-based Learning vs Lecture in Integrated Management of Childhood Illness Workshops. J Postgrad Med Edu Res 2016;50(3):123-126.

Source of support: Nil

Conflict of interest: None

\section{INTRODUCTION}

The mortality of infants and children is still increasing in developing countries. ${ }^{1}$ The aim of the millennium

\footnotetext{
${ }^{1,4}$ Assistant Professor, ${ }^{2,3}$ Associate Professor

${ }^{1-3}$ Department of Pediatrics, Zanjan University of Medical Sciences, Zanjan, Islamic Republic of Iran

${ }^{4}$ Department of Epidemiology, Zanjan University of Medical Sciences, Zanjan, Islamic Republic of Iran

Corresponding Author: Fardin Assadi, Assistant Professor Department of Pediatrics, Zanjan University of Medical Sciences Zanjan, Islamic Republic of Iran, Phone: +00982433130001 e-mail: assadi_fardin@yahoo.com
}

development is to decrease children's mortality to twothirds till 2015. ${ }^{2}$ To reach this goal, a comprehensive approach to assess and treat ill child with primary health care consultants is essential. Therefore, the strategy of Integrated Management of Childhood Illness (IMCI) was compiled by UNICEF. ${ }^{3}$ Integrated Management of Childhood Illness is an education course usually held as workshops to combine class and clinical works, and several educational methods are used for a better understanding and performance. ${ }^{4}$ A review of interventional studies in developing countries shows that a simple distribution of guidelines is not successful. ${ }^{5}$ Many studies show that the education of health care professionals in IMCI programs, although useful, is not sufficient. ${ }^{4,6-8}$ Regarding the significance of IMCI workshops, the need to use creative and new educational methods for a better understanding and performance is very important.

Problem-based learning (PBL) is an educational method, e.g., commonly used in medical schools in different countries and has the advantage of better knowledge retention. In PBL, students specify their own learning objectives by using the presented scenarios. ${ }^{9}$ By working through these scenarios or problems, students will be able to think critically, generate ideas, and acquire the needed skills. ${ }^{10}$ Although supporters of PBL determine that this method increases depth training, gives better performance in examinations, ${ }^{11}$ and increases motivation, the most important disadvantage is that it is time-consuming. ${ }^{12}$ Studies conducted to compare PBL with traditional lecture presentation show different results. In some studies the knowledge of trainees in PBL method is not better than lecture presentation. ${ }^{13-18}$ In contrast, many studies show that students get better scores in PBL teaching method. ${ }^{11,19-22}$ Regarding the importance of education in IMCI workshops, we conducted the present study to compare PBL with lecture presentation on knowledge and satisfaction of our medical students in Zanjan University of Medical Sciences.

\section{MATERIALS AND METHODS}

In this interventional crossover study, 44 clinical medical students were studied in pediatric ward during 12 months. In each 3 months about 10 medical students, who were introduced to pediatric ward for their internship, were 
randomly divided into two groups and the IMCI workshop were completed in 2 weeks. Two common topics of the workshop, "loss of consciousness" (LOC) and "management of diarrheal diseases", were chosen. For the first group, "loss of consciousness" was taught as lecture presentation and the same topic was presented as PBL for the second group of students. After 2 weeks, "the management of diarrheal diseases" was presented as PBL for the first group of students and as lecture presentation for the second group. The lectures were presented for both topics by the same person who attended as the tutor in PBL courses as well. Four groups of students completed the pediatric course in 3 months period and the duration of the study was 12 months.

Three pediatricians were consulted to design case scenarios based on educational goals. In the first session, the goal of the study, teaching method, and the way of the evaluation were explained to the investigation group. In each session, the designed scenarios with the chief complaints, presenting illness, physical exams, and paraclinical tests were introduced, and questions about etiology, differential diagnosis, treatment plans, and referral of the patient were given to the students. In the following sessions students stated their educational needs and were referred to information sources. They discussed and debated about the multiple aspects of the problems and their solutions and if needed paraclinical documents, test results, and radiographies were presented to the students. A sense of competition as well as assistance was created among them. Therefore, after discussion about the etiology, differential diagnosis, and the approach to the problem, the students defined the algorithms for diagnosis and treatment plans. The role of the tutor was to facilitate PBL courses.

At the end of the sessions each group printed their solutions and the representative of each group presented the results. Multiple solutions were compared; the questions were answered; and the best solutions were chosen by the students. At the end of pediatric courses and after the completion of PBL courses in all groups, an exam was hold to assess their knowledge. The knowledge questionnaire had eight questions. In each topic four almost similar questions, one with the first taxonomy, one with the second taxonomy, and two with the third taxonomy were asked. In each topic, the total score was 4 . The validity of this questionnaire was determined by content validity defined by pediatrics academics consult.

Also, the students completed a questionnaire about their satisfaction of the educational methods. The satisfaction questionnaire consisted of seven questions that compared PBL and lecture in the field of practical usefulness, knowledge retention, attractiveness, motivation, learning quality, student preference and answering exam questions, and its validity was assessed in previous studies. ${ }^{23}$

The data was analyzed by Statistical Package for the Social Sciences (SPSS) version 11.5. The results are shown by number, percent, mean, and standard deviation. Independent $t$-test and paired $t$-test were used to compare study groups. p-values less than 0.05 were assumed as statistically significant.

\section{RESULTS}

This study was conducted in four consequently trimester, in 1 year. After performing four crossover intervention in four groups of students, and gathering the results of four exams with different questions but similar designs, the results were studied.

In the intervention group of "loss of consciousness," highest score was 4 and the lowest score was 2 . The mean score in this group was $3.27(\mathrm{SD}=0.70)$. In the control group in which loss of consciousness was presented as lecture presentation, the highest score obtained was 4 but the lowest was 1 with the mean of $2.45(\mathrm{SD}=0.91)$. Students' score in control group was less than intervention group and this difference was statistically significant $(\mathrm{p}=0.002)$.

In the intervention group in which dehydration was held as PBL, the maximum score obtained by the students was 4 and the lowest was 2 with the mean of 3.36 $(\mathrm{SD}=0.66)$. In control group in which "management of diarrheal diseases" was presented as lecture presentation the highest score was 4 and the lowest was 1 with the mean of 2.09 ( $\mathrm{SD}=0.87)$. The scores of the students in the control group was less than the intervention group and this difference was statistically significant $(\mathrm{p}<0.001)$.

In another analysis the scores of each student obtained in PBL and lecture presentation were compared. It is obvious that in this analysis the topics would be different that the student's mean score in lecture presentation of a topic was compared with its score in the other topic held as PBL. Considering that the mean scores of the two topics were not much different, it can be consumed that the two topics were similar in difficulty. Surprisingly, by the use of paired t-test analysis, we found that each student's score in PBL method was significantly higher than lecture presentation $(p<0.001)$ and each student's score in the topic held as PBL is compared with its score in lecture presentation in Graphs 1 and 2. The mean score of each student in topic held as PBL was $3.32(\mathrm{SD}=0.67)$; the mean score in topic presented as lecture (control) was $2.27(\mathrm{SD}=0.9)$. This difference was statistically significant $(p<0.001)$. In other words, the mean score of each student in PBL was $25 \%$ more than lecture presentation. 


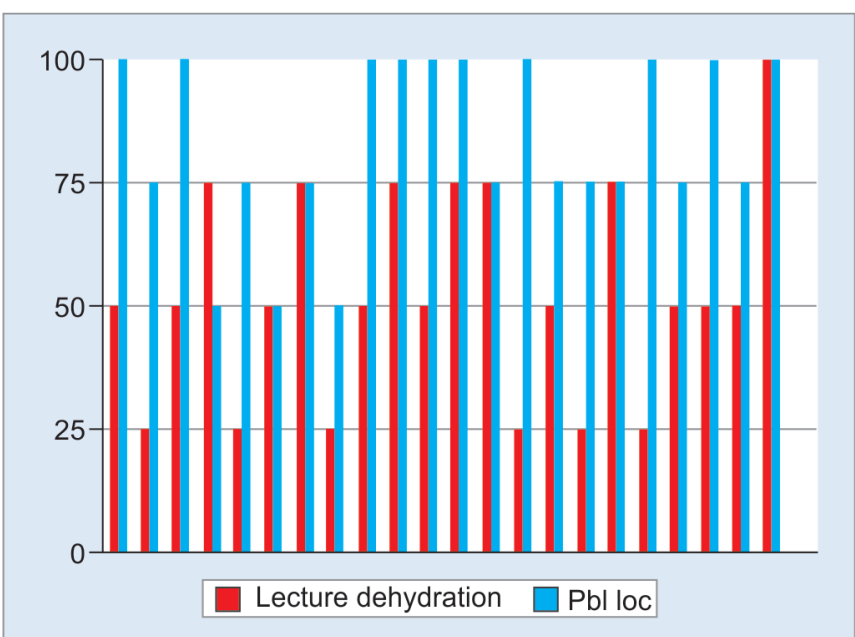

Graph 1: Each student's score in PBL of LOC and lecture of "management of diarrheal diseases" (dehydration)

All the students completed the satisfaction questionnaire. Twenty-five students (56.8\%) preferred PBL in learning quality, but 19 students $(43.2 \%)$ preferred lecture presentation. Twenty-eight students preferred PBL compared to 18 students (36.4\%) who preferred lecture for knowledge retention. For practical usefulness 23 students $(52.3 \%)$ voted for PBL compared to $21(47.7 \%)$ who voted for lecture. Thirty students $(68.2 \%)$ found PBL more attractive and $14(31.6 \%)$ preferred lecture. Forty $(90.9 \%)$ students stated that with PBL they had more motivation to study but $4(9.1 \%)$ had more motifs with lecture. Thirty-six students $(81.8 \%)$ proposed to use the PBL as the preferred educational method and $8(18.2 \%)$ preferred lecture. In contrast, $34(77.3 \%)$ students stated that with lecture presentation they could answer better the exams questions but only $10(22.7 \%)$ preferred PBL.

\section{DISCUSSION}

In this crossover interventional study, students got statistically significant higher scores in both topics in PBL method. These results are similar to the results of McParland who stated that students had a better performance in both multiple choice questions and the viva with PBL method but he did not found any difference in their attitude or learning style. ${ }^{10}$ Although, in our study, it seems that students had a better attitude in PBL method.

In Koleini's study, the mean score in intervention group was 1.5 points more than the control (lecture) group and the difference was statistically significant. ${ }^{24}$ In our study, the scores of the intervention group was approximately 1 point higher than control group. Similar results were found in studies of $\operatorname{Lin}^{20}$ and Moreno-López. ${ }^{21}$

On the contrary, in some studies PBL was shown to be ineffective in increasing the knowledge of students. In the study by Carrero et $\mathrm{al}^{14}$ on 52 anesthesiologists in

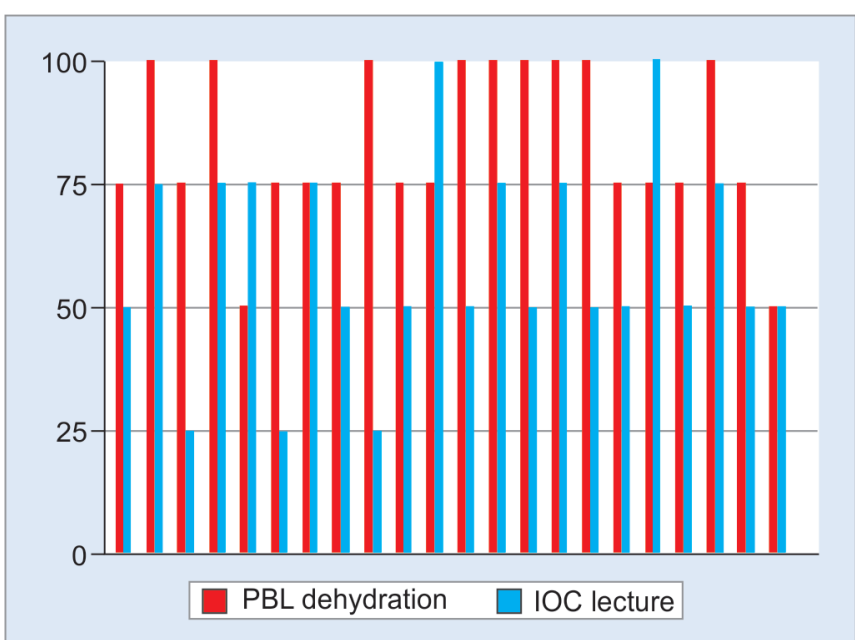

Graph 2: Each student's score in PBL of "management of diarrheal diseases" (dehydration) and lecture of LOC

continuous medical education courses, no statistically significant difference in their knowledge was observed between control and intervention groups. Goodyear ${ }^{15}$ has not shown a significant difference in knowledge of 14 senior house officers after PBL courses comparing with lecture, although the participants preferred the PBL method. The priority of this study was the fact that the assessment was done with both OSCE and multiple choice questions. Although in Smith's investigation, the performance of trainees in PBL group was better than control group, their knowledge did not differ significantly. ${ }^{13}$

It is obvious that in many studies these two methods were compared whit different results. The difference can be due to the fact that the groups were not exactly matched, the interval to the exam time could be close to lectures, the tutor and the lecturer were not the same person or the lecturer who would design the exam questions had emphasized on key points.

The crossover design of the study could eliminate the confounding factors affecting the scores of the matched groups, such as personal characteristics and IQ, memory, commitment and motivation of students. The tutor and the lecturer in both topics was the same person that reduces the influence of factors like the knowledge, art of teaching, emphasizing key points and the manner of expression of the lecturer and facilitator. The priority of our study was its crossover design to reduce intersubject variability.

Regarding students satisfaction in our study, $56.82 \%$ of students preferred PBL in increasing learning quality, $63.64 \%$ in knowledge retention, $52.27 \%$ in practical usefulness, $68.18 \%$ in class attractiveness, and $90.91 \%$ in motivation to study. But, only $22.73 \%$ of students find PBL to be more effective in answering exam questions.

Our results were similar to the results of Kawaiy's study in which dental students preferred PBL in the 
context of the content of class and clinical inference ability and self study, but they did not want to take the same system class repeatedly. Dehkordi ${ }^{25}$ has stated that PBL was more effective in learning, attitude, and behavior of nursing students. In the study of Mousaai Fard, nursing students preferred PBL in increasing learning quality, knowledge retention, practical usefulness, class attractiveness, motivation to study and answering exam questions. ${ }^{23}$ In our study, only $22.73 \%$ of students preferred PBL method in answering exam questions compared to $51.85 \%$ of Mousaai Fard's study. This could be due to the fact that in their study the knowledge of students was not assessed. In Zarshenas's survey, students declared that PBL was effective in increasing motivation, knowledge retention, and learning quality, which was similar to our results. ${ }^{26}$ However, the sole study we found in which the students were less satisfied with PBL was the Smiths study. ${ }^{13}$

\section{CONCLUSION}

Problem-based learning is a useful educational method that is more successful than lecture in increasing student's knowledge. This method is attractive and more effective in knowledge retention. The use of this method in workshops is highly recommended.

\section{REFERENCES}

1. Liu L, Johnson HL, Cousens S, Perin J, ScottS, Lawn JE, Rudan I, Campbell H, Cibulskis R, Li M, et al. Global, regional, and national causes of child mortality: an updated systematic analysis for 2010 with time trends since 2000. Lancet 2012 Jun;379(9832):2151-2161.

2. Rajaratnam JK, Marcus JR, Flaxman AD, Wang H, LevinRector A, Dwyer L, Costa M, Lopez AD, Murray CJ. Neonatal, postneonatal, childhood, and under-5 mortality for 187 countries, 1970-2010: a systematic analysis of progress towards Millennium Development Goal 4. Lancet 2010 Jun;375(9730):1988-2008.

3. Lulseged S. Integrated management of childhood illness: a review of the Ethiopian experience and prospects for child health. Ethiop Med J 2002 Apr;40(2):187-201.

4. Horwood C, Voce A, Vermaak K, Rollins N, Qazi S. Experiences of training and implementation of integrated management of childhood illness (IMCI) in South Africa: a qualitative evaluation of the IMCI case management training course. BMC Pediatr 2009 Oct 1;9:62.

5. Rowe AK, de Savigny D, Lanata CF, Victora CG. How can we achieve and maintain high-quality performance of health workers in low-resource settings? Lancet 2005 Sep 17-23;366(9490):1026-1035.

6. Rowe AK, Onikpo F, Lama M, Osterholt DM, Rowe SY, Deming MS. A multifaceted intervention to improve health worker adherence to integrated management of childhood illness guidelines in Benin. Am J Public Health 2009 May;99(5): 837-846.

7. Pariyo GW, Gouws E, Bryce J, Burnham G, Uganda IMCI Impact Study Team. Improving facility-based care for sick children in Uganda: training is not enough. Health Policy Plan 2005 Dec;20(Suppl 1):i58-i68.
8. Horwood C, Vermaak K, Rollins N, Haskins L, Nkosi P, Qazi S. An evaluation of the quality of IMCI assessments among IMCI trained health workers in South Africa. PLoS One 2009 Jun 17;4(6):e5937.

9. Wood DF. ABC of learning and teaching in medicine: problem based learning. BMJ 2003;326(7384):328-330.

10. Onyon C. Problem-based learning: a review of the educational and psychological theory. Clin Teach 2012 Feb;9(1):22-26.

11. McParland M, Noble LM, Livingston G. The effectiveness of problem-based learning compared to traditional teaching in undergraduate psychiatry. Med Educ 2004 Aug;38(8):800-801.

12. Kilroy DA. Problem based learning. Emerg Med J 2004 Jul;21(4):411-413.

13. Smits PB, de Buisonjé CD, Verbeek JH, van Dijk FJ, Metz JC, ten Cate OJ. Problem-based learning versus lecture-based learning in postgraduate medical education. Scand J Work Environ Health 2003 Aug;29(4):280-287.

14. Carrero EJ, Gomar C, Fábregas N, Penzo W, Castillo J, Villalonga A. Problem/case-based learning compared to lectures for acquiring knowledge of air embolism in continuing medical education. Rev Esp Anestesiol Reanim 2008 Apr;55(4):202-209.

15. Goodyear HM. Problem based learning in a junior doctor teaching programme. Arch Dis Child 2005 Mar;90(3):275-278.

16. Khan H, Taqui AM, Khawaja MR, Fatmi Z. Problem-based versus conventional curricula: influence on knowledge and attitudes of medical students towards health research. PLoS One 2007 Jul 18;2(7):e632.

17. Johnston JM, Schooling CM, Leung GM. A randomisedcontrolled trial of two educational modes for undergraduate evidence-based medicine learning in Asia. BMC Med Educ 2009 Sep 29;9:63.

18. Chang G, Cook D, Maguire T, Skakun E, Yakimets WW, Warnock GL. Problem-based learning: its role in undergraduate surgical education. Can J Surg 1995 Feb;38(1):13-21.

19. Tack CJ, Plasschaert AJ. Student evaluation of a problemoriented module of clinical medicine within a revised dental curriculum. Eur J Dent Educ 2006 May;10(2):96-102.

20. Lin CF. A comparison of problem-based learning and conventional teaching in nursing ethics education. Nurs Ethics 2010 May 1;17(3):373-382.

21. Moreno-López LA. Problem-based learning versus lectures: comparison of academic results and time devoted by teachers in a course on Dentistry in Special Patients. Med Oral Patol Oral Cir Bucal 2009 Nov 1;14(11):e583-e587.

22. Anyaehie US, Nwobodo E, Njoku CJ, Inah GA. Comparative evaluation of active learning and the traditional lectures in physiology: a case study of 200 level medical laboratory students of Imo State University, Owerri. Niger J Physiol Sci 2007 Jun-Dec;22(1-2):117-121.

23. Fard MM, Amini K. Comparison of two teaching methods (Lecturing and PBL) from the point of Zanjan Medical University Nursing Student View. J Med Edu Dev 2010;2(3):60-68.

24. Koleini N, Farshidfar F, Shams B, Salehi M. Problem based learning or lecture, a new method of teaching biology to first year medical students: an experience. IJME 2003 Autumn;3(2):57-63.

25. Dehkordi AH. The impact of problem-based learning and lecturing on the behavior and attitudes of Iranian nursing students. A randomized controlled trial. Dan Med Bull 2008 Nov;55(4):224-226.

26. Zarshenas L, Momeni Danaei S, Oshagh M, Salehi P. Problem based learning: an experience of a new educational method in dentistry. IJME 2010;10(2):171-179. 